\title{
The Conflict Paradigm in Sociology and the Study of Social Inequality: Paradox and Possibility
}

\author{
Richard M. Simon ${ }^{*}$
}

Conflict theory is one of the major paradigms utilized in contemporary sociology. Conflict theory takes competition between social groups for scarce resources, and the inequalities that result, to be fundamental elements of social structure. However, at the same time, the empirical study of social inequalities has revealed that group conflict produces a great deal of human misery and frustration, and one important dimension of conflict theory is the study of how to redress inequalities in power, status, and material conditions between social groups. This produces a paradox, in which social conflict and its resulting inequalities are taken to be fundamental to social structure, and yet conflict sociologists and policy makers attempt to write equality into social structure. This paper explores the theoretical foundations of the conflict paradigm in sociology, and in doing so exposes the possibilities for dismantling social conflicts and the inequalities that result from them before they become institutionalized in social structure. It is argued that the liberal method of managing inequality ex post facto traditionally adopted by conflict sociologists is inadequate because it fails to account for the symbolic roots of inequality, and that social inequalities cannot be overcome until sociologists develop a means of intervening in the creation of symbols in micro rituals before they become institutionalized into groups in conflict. It is proposed that a conflict sociology rooted in individualist anarchism that targets the reproduction of culture at the individual-level is a promising avenue for addressing the symbolic production of social conflict. [Article copies available for a fee from The Transformative Studies Institute. E-mail address: journal@transformativestudies.org Website: http://www.transformativestudies.org $\mathbb{0} 2016$ by The Transformative Studies Institute. All rights reserved.]

KEYWORDS: Social Conflict, Inequality, Anarchism, Critical Theory, Symbolic Interaction, Culture.

\footnotetext{
* Richard M. Simon, Ph.D., earned his doctorate in sociology from the Pennsylvania State University In 2011. He is currently an Assistant Professor of Sociology at the University of Alabama in Huntsville. His Areas of interest include: public attitudes toward and evaluations of sciences and technologies, gender, social theory, quantitative methods, and anarchist sociology. His Research in anarchist sociology currently involves establishing a theoretical synthesis between anarchist political philosophy, conflict sociology, and symbolic interactionism for the purpose of laying the theoretical groundwork necessary for dismantling civilization. Address correspondence to: Dr. Richard M. Simon, University of Alabama in Huntsville, 301 Sparkman Drive, Huntsville, Alabama 35899; e-mail: rs0050@uah.edu.
} 